\title{
Properties of Polymer Composites with Cellulose Microfibrils
}

\author{
Denis Mihaela Panaitescu, Adriana Nicoleta Frone, Marius Ghiurea, \\ Catalin Ilie Spataru, Constantin Radovici and Michaela Doina Iorga \\ National Institute of Research and Development in Chemistry and Petrochemistry \\ Romania
}

\section{Introduction}

Plastic materials are indispensable in our lives but they are an important source of environmental pollution. In order to reduce the environmental load generated from the disposal of used plastic materials, a growing interest has been focused on biodegradable polymers based materials. These polymers can be completely converted into water and carbon dioxide by the action of microorganisms after disposal.

Owing to their good mechanical properties, polymer composites with micro or nano cellulose fibers are promising substitutes for glass-fiber-containing composites in many industrial fields like automotive, construction, electronics, biomedicine, cosmetics, and last but not least, the packaging industry. Among the advantages of using cellulose fibers as reinforcements in polymer composites renewability, low cost, low density, low energy consumption, high specific strength and modulus, high sound attenuation, low abrasivity and relatively reactive surface are the most important. Cellulose fibers modified at nanometer size induce much higher mechanical properties to polymer matrices as regard to common cellulose fibers because of their higher crystallinity and mechanical properties combined with higher surface area and better interfaces.

The production of nano-scale cellulose fibers and their application in composite materials has gained increasing attention in the past two decades (Hubbe et al., 2008). Two main methods have been used to generate nano-scale cellulose fibers: the chemical way, mainly by strong acid hydrolysis, which removes the amorphous regions of cellulose fiber and produces nano-size fibrils and the mechanical method, by high pressure refiner treatment (Chakraborty et al., 2005), grinder treatment (Taniguchi and Okamura, 1998), microfluidizer (Zimmermann et al., 2004), and high-pressure homogenizer treatment (Istvan and Plackett, 2010).

In this chapter the discussion is focused on the physical and mechanical properties of polyvinyl alcohol (PVA) as a biodegradable matrix reinforced with three types of cellulose fibers prepared by different methods. This chapter will first discuss the most used methods for cellulose nanofibers preparation and the reinforcing effect of these cellulose fibers in different polymer matrices. This will be followed by the experimental results obtained in our laboratory on PVA composites prepared with cellulose fibers isolated by mechanical treatment, acid hydrolysis and ultrasound treatment. The isolated cellulose fibers were 
characterized by scanning electron microscopy (SEM) and X-ray diffraction (XRD) and PVA composites, prepared through film casting method, by $\mathrm{XRD}$, thermal analysis and mechanical characterization.

\section{State of the art}

Cellulose was rediscovered at the end of the last century due to nanoscience and improved technologies available for the disintegration of cellulose in submicron and nanosize fibers. The native cellulose molecule consists of linear glucan chains with repeating (1-4)- $\beta$ glucopyranose units. The supramolecular structure of cellulose is very complex and it has been the subject of many studies (Eichhorn et al., 2010).

In living plants cellulose occurs in fibers, the cell wall of wood fibers consisting of repeated crystalline structures resulted from the aggregation of cellulose chains, termed microfibrils. These microfibrils, with high aspect ratio, are surrounded by an amorphous matrix of hemicelluloses and lignin. Besides wood, bast fibers (Cao et al., 2008; Li and Pickering, 2008; Shaikh et al. 2009; Belhassen et al., 2009), agricultural residues (El-Sakhawy and Hassan, 2007; Fama et al., 2009), leaf fibers (de Rodriguez et al., 2006; Zuluagaet al., 2009), bacterial cellulose (Nakagaito et al., 2005; Yano et al., 2008), the shell of some fruits and vegetables (Chen et al., 2009; Rosa et al., 2010) or tunicates (Petersson and Oksman, 2006) were used as sources for cellulose nanofibers preparation. Among the methods of nanofiber isolation, the most used are: mechanical disintegration, acid hydrolysis and biological treatments. Mechanical treatments involve conventional refining procedures (Hubbe et al., 2008), crushing and cryocrushing (Bhatnagar and Sain, 2005; Panaitescu et al., 2007a; Alemdar and Sain, 2008) or high pressure homogenization of cellulose source suspended in water (Lee et al., 2009a). Chakraborty isolated cellulose fibers with submicron diameters by combining the severe shearing in a refiner with high-impact crushing under liquid nitrogen (Chakraborty et al., 2005).

Mechanical treatments have some disadvantages related to the high energy required in the process and to the high degree of inhomogenity, the resulted material containing larger fibrils in addition to microfibrils (Nakagaito and Yano, 2004; Nakagaito and Yano, 2005; Andresen et al., 2006; Andresen and Stenius, 2007; Stenstad et al. 2008).

Chemical treatments involve mainly acid and alkaline hydrolysis. Acid hydrolysis leads to the isolation of micro and nanofibers with a high degree of crystallinity by removing the amorphous regions of the raw cellulosic material. Using sulfuric acid, a negatively charged surface of the cellulose fibers can be obtained, through the esterification of hydroxyl groups by the sulfate ions, which prevents the agglomeration of fibers.

Many researchers have successfully used this method, alone or in combination with others methods, to obtain cellulose nanofibers (Zhang et al., 2007; El-Sakhawy et al., 2007; Moran et al., 2008; Chen et al., 2009): Bondenson et al. (2006) treated microcrystalline cellulose (MCC) with sulfuric acid in concentration of $63.5 \%(\mathrm{w} / \mathrm{w})$ and isolated cellulose whiskers with an aspect ratio between 20 and 40, Lee et al. (2009b) obtained nanocellulose fibers by hydrobromic acid hydrolysis of MCC, an increasing in MCC crystallinity being reported, Rosa et al. (2010) obtained cellulose whiskers with diameters as low as $5 \mathrm{~nm}$ and aspect ratio of up to 60 by sulfuric acid hydrolysis of coconut husk fibers.

Degradation of the cellulosic substrate may also occur in the presence of microorganisms (fungi, bacteria) or, directly, with enzymes. Enzymatic treatment of cellulose was performed by Henriksson et al. (2007) who reported the obtaining of cellulose nanofibers from two 
different commercial bleached wood sulphite pulps. Li et al. (2008) reported that removal of non-cellulosic components from cellulose fibers by enzyme treatment can increase the crystallinity, thermal stability and the amount of -OH groups of the treated fibers.

New and environmental friendly methods for cellulose nanofibers isolation were also tested in laboratory conditions. Ultrasonication had been used alone or in combination with other methods (e.g. acid hydrolysis) to obtain cellulose fibers. Filson and Dawson-Andoh (2009) obtained nanofibers with an average diameter between 21 and $23 \mathrm{~nm}$ applying this method. Application of cellulose nanofibers in polymer reinforcement is a relatively new research field. Two directions could be detected: research studies which explore the development of nano-bio-plastics as fully biodegradable nanocomposites and studies aimed at dispersing cellulose nanofibers in non-biodegradable, petroleum derived polymers. Polymer composites containing cellulose nanofibers were prepared with polyvinyl alcohol (PVA), polylactide (PLA), starch and polycaprolactone but also with polyethylene or polypropylene. Improvement in term of brittleness, thermal stability or barrier properties were signaled in case of biodegradable polymers reinforced with cellulose nanofibers (Iwatake et al., 2008; Chen et al., 2009; Fama et al., 2009; Pandey et al., 2009; Suryanegara et al., 2009; Bledzki et al., 2009; Chang et al., 2010). Cellulose fibers reinforcement could be a good solution for starch, which is a low cost source of biodegradable composites but a material with very poor mechanical properties. Dufresne and Vignon $(1998,2000)$ reported an improvement by a factor of 3.5 of the tensile modulus of starch at $50 \mathrm{wt} \%$ cellulose fibers addition. PLA is a commercially available biopolymer with similar properties to petroleum derived thermoplastics. Some drawbacks like brittleness and low thermal stability restrict its applications. Using cellulose fibers $(10 \mathrm{wt} \%)$ and a solvent exchange method, Iwatake et al. (2008) succeeded in fabricating a composite sheet with uniform filler distribution showing an increase of Young's modulus and tensile strength of 40 and $25 \%$ respectively. Chemical modification of cellulose has been explored as a route for improving filler dispersion in hydrophobic polymers such as polyethylene or polypropylene (Panaitescu et al., 2007b; Rahman et al., 2009; Yanjun et al., 2010).

PVA is a water-soluble and biodegradable polymer with excellent chemical resistance and an interesting material for biomedical applications. PVA has no toxic action on the human body being used to manufacture medicines cachets, yarn for surgery, controlled drug delivery systems (Tang et al., 2009). New fields of application regard cardiovascular devices (Millon and Wan, 2006), dialysis membrane, artificial cartilage, tissue engineering scaffold (Zhou et al., 2010). Development of ecofriendly packaging materials is still a challenging area and many studies are focused on the improvement of PVA mechanical and barrier properties by combination with other polymers or fillers in order to use it in the packaging industry (Sedlarik et al., 2006). For many other applications, mechanical properties of PVA should be substantially improved without damaging its valuable properties. Low cellulose fibers addition could be an appropriate solution. Many studies emphasized the effectiveness of large amount of cellulose fibers in improving mechanical properties of PVA. Zimmermann et al. (2004) reported an improvement of the elastic modulus and tensile strength of up to five times and three times, respectively, in the case of dispersing $20 \mathrm{wt} \%$ cellulose fibers in PVA. An increase of about five times of the tensile strength relative to the reference polymer was reported by Bruce et al. (2005) at $50 \mathrm{wt} \%$ cellulose fibers in PVA and an increase by a factor of 3.5 at the same concentration of fibers in the work of Leitner et al. (2007). Nevertheless, no increase in tensile strength and modulus was observed by Lu et al. (2008) above $10 \mathrm{wt} \%$ cellulose fibers in PVA. 
Despite the important publication activity dealing with cellulose nanofibers and related nanocomposites the application of such materials is quite limited. There are several reasons for this situation. One of them is the difficulty of the separation of plant fibers into smaller constituents with uniform and reproducible characteristics. Another reason is the high energy demands for most isolation processes. Problems concerning interfacial adhesion and uniform dispersion of the cellulose fibers in the polymer matrix delayed also the wide application of these materials.

Moreover, results obtained in different laboratories on polymer composite containing cellulose fibers are often contradictory because of many factors controlling the process like filler size and content, interface adhesion, fiber aspect ratio and orientation, fiber dispersion in the matrix and stress transfer efficiency through the interface (Dufresne et al., 2003). However, the role of nanofiber characteristics and aggregation in influencing macroscale properties of polymer matrix is not yet well understood.

Important research work was focused on studying the changes induced in PVA characteristics by high concentration of cellulose fibers prepared by different processes. These results were obtained in different laboratories and different conditions were applied in order to prepare PVA composite films. PVA is a polymer sensitive to preparation conditions so that significant changes may occur depending on the working atmosphere and heat treatments applied. Knowing the high influence of preparing and characterization conditions on PVA properties, it is difficult to select the proper system PVA/cellulose fibers for a target application based on existing information. Moreover, achieving improved mechanical properties with the less concentration of cellulose fibers is desirable for preserving transparency and flexibility of PVA films. For these reasons, we further describe research results obtained in our laboratory for monitoring the influence of cellulose fibers obtained by different treatments on the microscopic and macroscopic properties of PVA, all the samples being prepared in the same conditions. PVA composites were prepared by solution casting using low concentration ( $\leq 5 \mathrm{wt} \%$ ) of cellulose fibers obtained by mechanical treatment $(\mathrm{L})$, acid hydrolysis $(\mathrm{H})$ and ultrasound treatment $(\mathrm{U})$. The isolated cellulose fibers were characterized by scanning electron microscopy (SEM) and X-ray diffraction (XRD). PVA composites containing these fibers were characterized with the aim of determining thermal and mechanical behavior.

\section{Experimental part}

\subsection{Materials}

Polyvinyl alcohol, PVA 120-99, 1200 polymerization degree and 99\% hydrolysis degree was used as matrix. Microcrystalline cellulose (MCC) with a mean particle size of $20 \mu \mathrm{m}$ and an aspect ratio of 2 - 4, from Sigma-Aldrich, was used as raw material for the preparation of nanofibers and cellulose microfibers obtained from regenerated wood fibers (L) through mechanical treatment were donated by National Institute of Wood.

\subsection{Nanofibers isolation}

\section{(a) By ultrasonic treatment}

MCC with a mean particle size of $20 \mu \mathrm{m}$, as revealed by SEM image (Fig. 1), was dispersed under continuous stirring in distilled water $(1 / 500)$ and sonicated at $80 \%$ power for 20 minutes using an ultrasonicator type Vibra Cell VC505 (500 W, $20 \mathrm{KHz})$. In order to control 
the process temperature, the beaker with the cellulose suspension was put in a water bath with controlled temperature. The appearance of turbidity in the supernatant was a definite indication of the presence of cellulose nanofibers. Cellulose fibers suspension was obtained by decanting the supernatant into other vessel. Cellulose fibers - sample U was characterized by $\mathrm{X}$ ray diffraction after drying 4 hours at $40^{\circ} \mathrm{C}$.

(b) By acid treatment

MCC was dispersed in distillated water (1/10). The resulted suspension was placed in an ice bath and stirred while concentrated sulfuric acid was added by drop until the desired acid concentration of $63 \%$ was reached. The suspension was heated at $400^{\circ} \mathrm{C}$ while stirred for $5 \mathrm{~h}$. The obtained mixture was washed with distillated water using repeated centrifuge cycles (20 min at $7000 \mathrm{rpm}$, Universal 320R Ultracentrifuge) until a $\mathrm{pH}$ of 4 was reached. Further, the obtained sample of cellulose fibers $(\mathrm{H})$ was ultrasonicated (Elmasonic S40H, Elma) for five hours in an ice bath in order to avoid the sample overheating. Cellulose fibers - sample $\mathrm{H}$ was characterized by $\mathrm{X}$ ray diffraction after drying 4 hours at $40^{\circ} \mathrm{C}$.

(c) Cellulose fibers obtained through mechanical treatment $(\mathrm{L})$ were used as received.

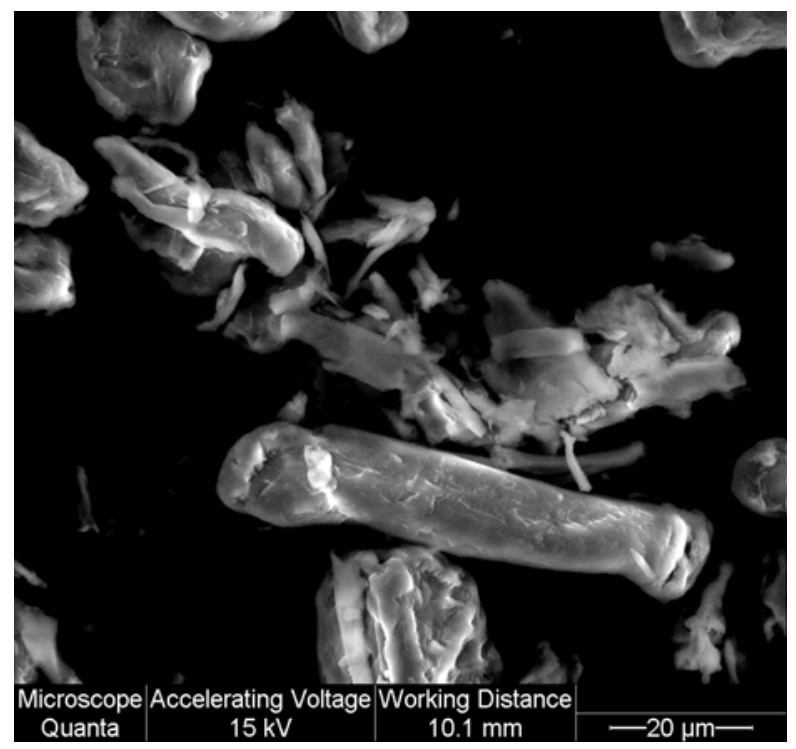

Fig. 1. SEM image of commercial microcrystalline cellulose (MCC)

\subsection{Nanocomposite films preparation}

In order to obtain PVA/cellulose fibers composite films with different filler concentrations, the required amount of PVA corresponding to a final concentration of $10 \%$ in the aqueous medium and the calculated amount of $\mathrm{L}, \mathrm{U}$ and $\mathrm{H}$ cellulose fibers suspensions to achieve 1 , 3 and $5 \mathrm{wt} \%$ filler concentration in the final composite were mixed using a high speed stirrer $\left(500 \mathrm{~min}^{-1}\right)$. The stirring was performed at $80^{\circ} \mathrm{C}$ for 3 hours, and the resulting mixture was degassed for approximately 15 minutes in an Elmasonic S40 H ultrasonic bath. The films were cast on a PET plate and were kept at room temperature for 2 days until they were completely dried and then removed from the PET plates and placed in a desiccator for two 
weeks before mechanical characterization. Neat PVA films were obtained under similar conditions.

\subsection{Characterization methods}

SEM micrographs of cellulose fibers were obtained with an environmental Quanta Scanning Electron Microscope 200, with a tungsten electron source in the following conditions: accelerating voltage $10-30 \mathrm{kV}$, no coating. The crystalline structure of cellulose fibers was determined by XRD with a DRON-UM diffractometer (horizontal goniometer BraggBrentano) using Co Ka radiation (wavelength $\lambda=1.79021 \AA$ ), scanning from the $2 \theta$ value of $5^{0}$ to $36^{0}$ at a scanning rate of $0.05^{0} / 5 \mathrm{sec}$. Samples were analyzed in reflection mode.

Mechanical behavior of composite films at room temperature was tested in tensile mode according to ISO 527-1:1993 Part 1 and ISO 527-3:1995 Part 3 by an Instron 3382. The Universal Testing Machine was equipped with a video extensometer for strain measurement and with a load cell of $1 \mathrm{kN}$ capacity. The following data: video axial strain at break (elongation at break), tensile stress at break (tensile strength), Young's modulus (tensile modulus) and other optional features were automatically display using the software of Instron 3382, Bluehill 2. Young's modulus on the strain channel with a start value of $0.05 \%$ and an end value of $0.25 \%$ was calculated by the system applying the least square fit algorithm to each region between the start and end value selecting the highest slope. The load cell of $1 \mathrm{kN}$ capacity, used for PVA composites tensile properties measurements has a sensitivity of $0.001 \mathrm{~N}$. Test specimens were cut to $110 \mathrm{~mm}$ (length) $\times 10 \mathrm{~mm}$ (width) $\times 0.035$ $0.045 \mathrm{~mm}$ (thickness) from the films maintained in desiccators, 7 specimens being tested for each sample. Tensile modulus was determined at a crosshead speed of $2 \mathrm{~mm} / \mathrm{min}$ and tensile strength and elongation at $10 \mathrm{~mm} / \mathrm{min}$. Lower crosshead speed was necessary for correct determination of tensile modulus as stipulated by ISO 527 Part 1. Differential scanning calorimetry (DSC) and thermogravimetric analysis (TGA) were performed on a SDT Q600 V20.9 from TA Instruments under Heliom flow (100 mL/min). The samples weighing between 5 and $10 \mathrm{mg}$ were packed in aluminium pans and placed in the DSC cell. The samples were tested from the ambient temperature to $600^{\circ} \mathrm{C}$ at a heating rate of $10^{\circ} \mathrm{C} / \mathrm{min}$. The DSC glass transition temperature $(\mathrm{Tg})$ was taken at the onset of the glass transition region. The PVA composite samples were conditioned for $24 \mathrm{~h}$ at $40{ }^{\circ} \mathrm{C}$ in a vacuum oven prior to thermal analysis.

\section{Results}

\subsection{Cellulose fibers characterization}

The three samples of cellulose fibers, $\mathrm{L}, \mathrm{H}$ and $\mathrm{U}$, were investigated by scanning electron microscopy (Fig. 2, 3a-c and 4). SEM image obtained for sample L (Fig. 2) revealed the distribution of fiber diameters ranging from 5 to $20 \mu \mathrm{m}$. The surface of $\mathrm{L}$ is smoother and the aspect ratio $1 / \mathrm{d}$ of 4 to 14, greater then the $1 / \mathrm{d}$ of MCC sample, ranging from 2 to 4 .

The acid hydrolysis of MCC is a heterogeneous process which involves the diffusion of acid into the cellulose fibers, and the subsequent cleavage of glycosidic bonds. Figures 3a-c are SEM micrograph of acid treated MCC after different time of acid hydrolysis $(2,4$ and 5 hours). Fig. 3a shows how the acid broke the MCC particle, attacking amorphous areas and releasing aggregates of cellulose microfibrils. Fig. $3 \mathrm{~b}$ shows that a big fraction of amorphous areas were entirely destroyed and cellulose crystallites in needle form released. Portions with agglomerated microfibrils could also be observed. 


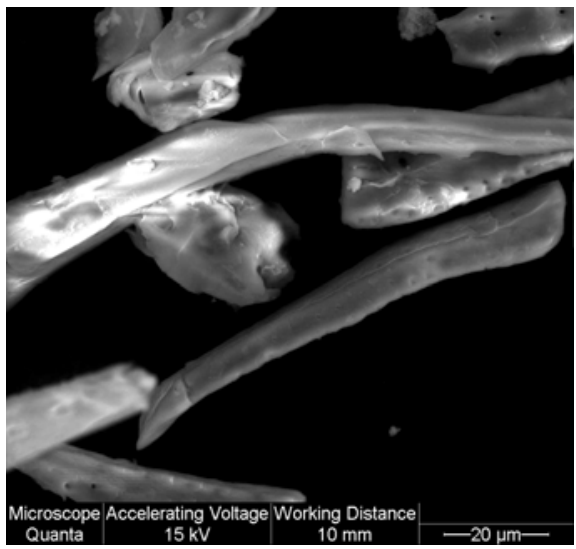

Fig. 2. SEM image of $L$ type cellulose fibers

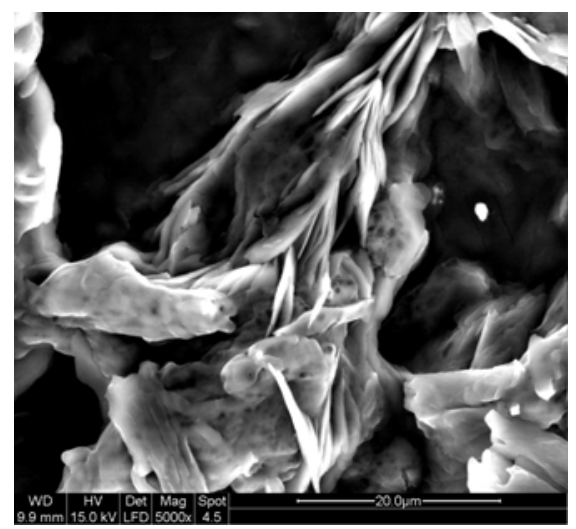

(a)

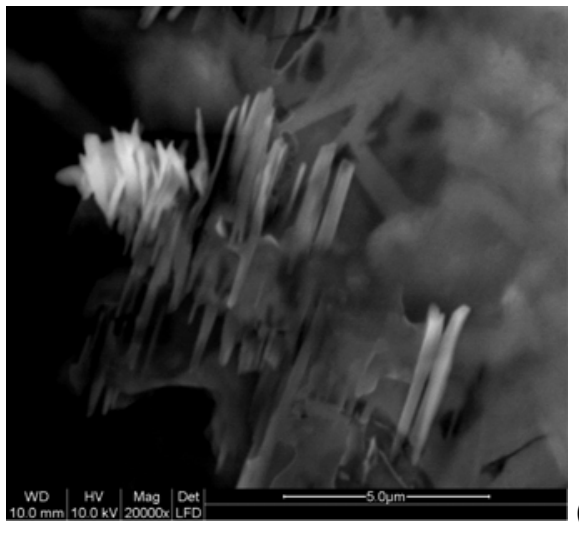

(b)

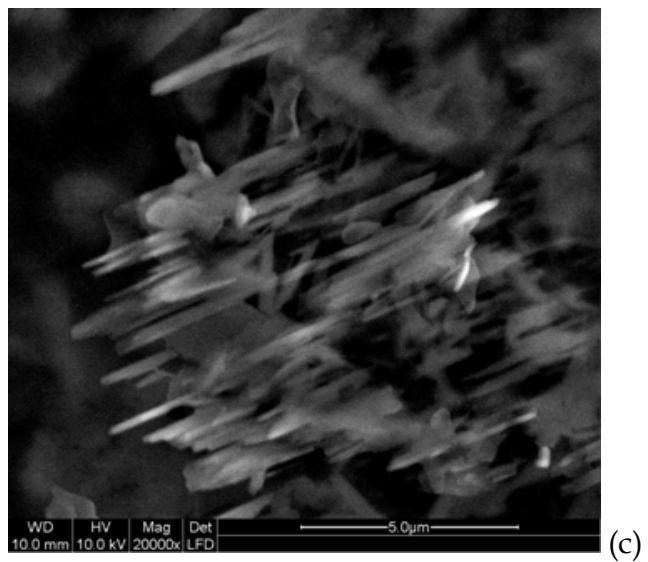

Fig. 3. SEM micrographs of (a) the first stages of acid attack of MCC, (b) releasing of cellulose microfibrils aggregates and (c) cellulose fibers type $\mathrm{H}$ 
In Fig. 3c rod like cellulose microfibrils with diameter of $100-400 \mathrm{~nm}$ and aspect ratio of 10 to 20 are observed. Cellulose fibers with smaller diameters can not be detected in SEM images, at this magnitude. It is presumed that the further ultrasonic treatment destroyed the agglomerates.

SEM micrograph of $U$ type cellulose fibers (Fig. 4) shows that MCC particles are entirely disintegrated into fragments with different shapes and size by sonication treatment. The effectiveness of MCC defibrillation process is very high, particles and fibers with a diameter of $20-800 \mathrm{~nm}$ being observed. Individual particles but also large aggregates of cellulose fragments can be easily observed. It is possible that a re-aggregation to take place, promoted by the strong hydrogen bonding between the individual cellulose whiskers prepared by ultrasonication. The heterogeneity of shapes and size is very great in this sample because of the high energy involved in ultrasonication, so that o separation process was imperative for removing higher size aggregates of cellulose fibers.

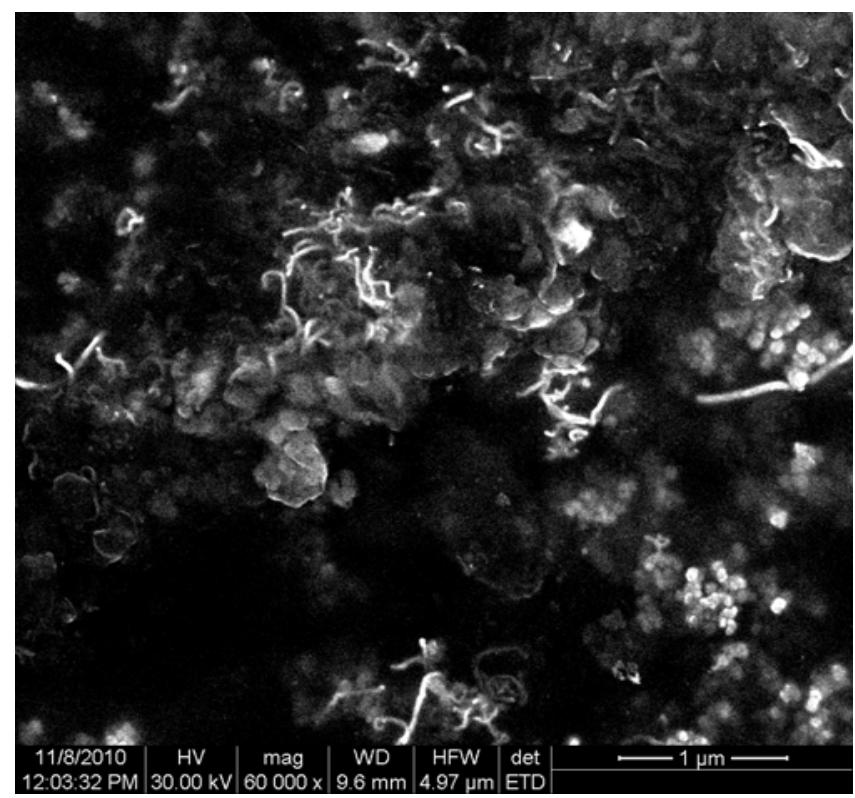

Fig. 4. SEM image of cellulose fibers prepared by ultrasonication

X-ray diffraction patterns of MCC and cellulose fibers (L, H and $\mathrm{U}$ ) are shown in Fig. 5. The characteristics peaks originated from cellulose I are visible for all the samples at the same values of $2 \theta\left(17.3^{\circ}, 18.9^{\circ}, 26.2^{\circ}\right)$. These values correspond to the interplanar spacings of the three principal planes (101), (101) and (002) of the monoclinic unit cell of cellulose: $d_{101}=$ $5.99 \AA, d_{10 \overline{1}}=5.40 \AA$ and $d_{002}=3.95 \AA$, respectively. Very close values for $2 \theta$ were reported by Lee et al. (2009b) taking into account the different wavelength of CuKa radiation used. In the case of sample L the two first peaks are not separated forming a broad peak, probably because of the more complex structure of sample L which contain beside celluloses, hemicelluloses and lignin. 


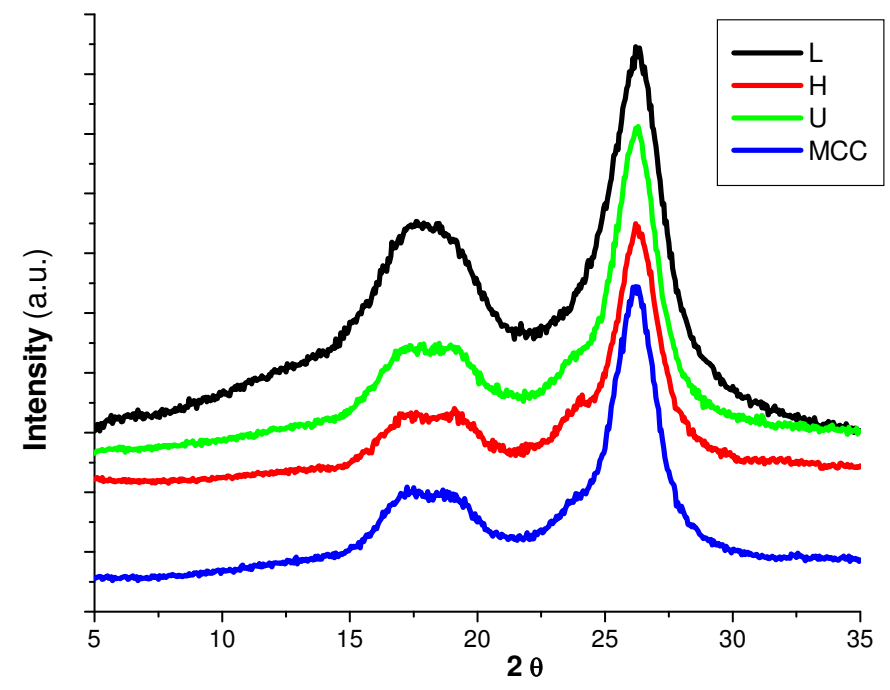

Fig. 5. X-ray diffraction patterns of MCC and cellulose fibers (samples L, H and U)

\subsection{Polymer composites characterization}

a. Mechanical characterization

The tensile strength, elongation at break, and elastic modulus of the PVA/cellulose fibers composites compared with those of unreinforced PVA are shown in Figs. 6 - 8.

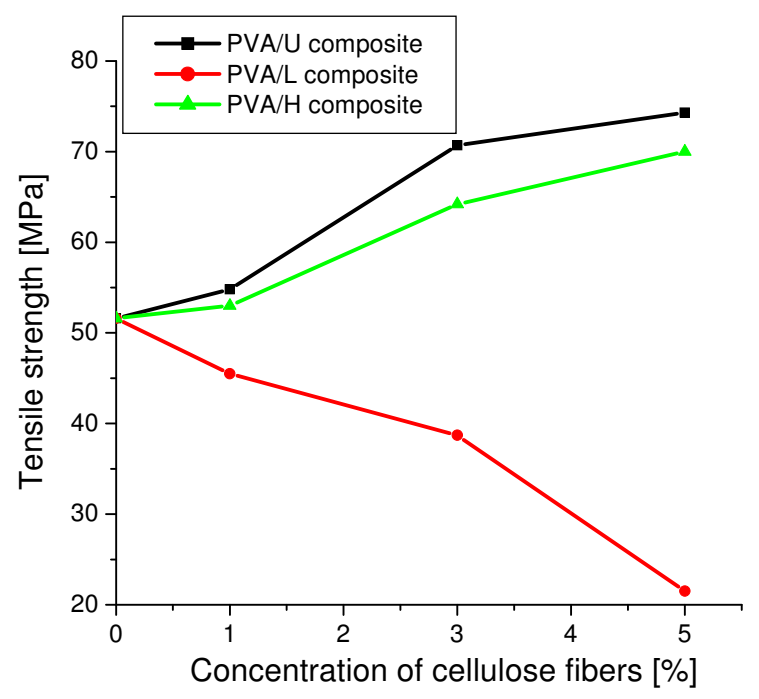

Fig. 6. Tensile strength of neat PVA and PVA reinforced with cellulose fibers $U, L$ and H 


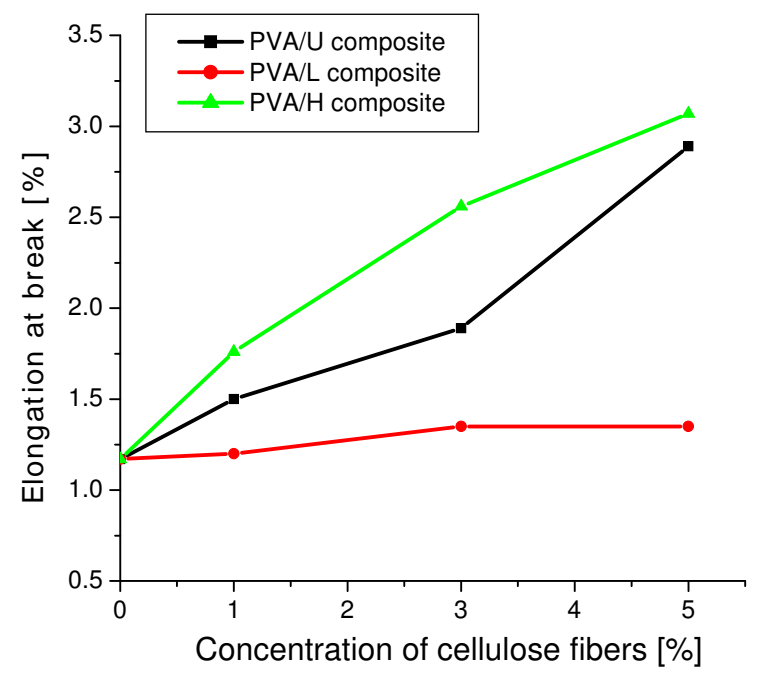

Fig. 7. Elongation at break of neat PVA and PVA reinforced with cellulose fibers $\mathrm{U}, \mathrm{L}$ and $\mathrm{H}$

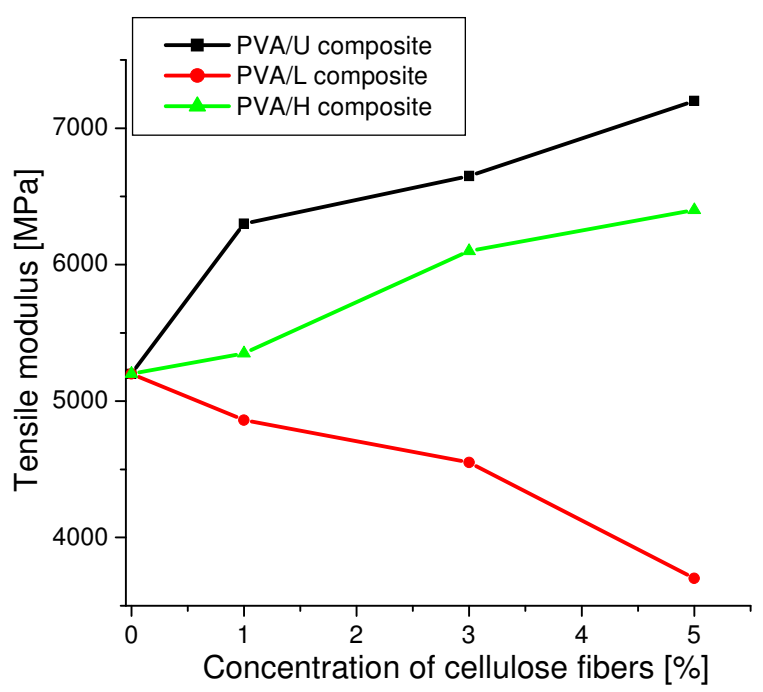

Fig. 8. Tensile modulus of neat PVA and PVA reinforced with cellulose fibers $U, L$ and $H$ 
It is apparent that the three types of fibers differently influence the mechanical properties of PVA matrix. $\mathrm{U}$ and $\mathrm{H}$ fibers lead to an improvement of mechanical properties, both the strength and modulus and elongation at break being enhanced and the type $L$ to a decrease in strength and stiffness. The observed differences are mainly due to the different size of fibers, $\mathrm{U}$ and $\mathrm{H}$ fibers having diameters on the nanoscale while $\mathrm{L}$ being micron sized fibers.

It is known that an important increase in strength and stiffness of polymer matrix can be obtained at concentrations above $30 \%$ of micron sized cellulose fibers, lower concentration of $20-25 \%$ being effective only in the case of a good treatment of fibers or coupling agent adding. In these composites, elongation at break knows significant decreases, polymer matrix ductility being severely altered by micron sized fibers (Bledzki et al., 2003; Ganster et al., 2006). Hence, it was not expected that the low concentration of L fibers could improve PVA mechanical properties.

In contrast to conventional filled polymer systems where the increase of strength and stiffness is accompanied by an important decrease of ductility, in nanocomposites a simultaneous increase of Young's modulus, tensile strength and elongation could appear, especially in the case of strong filler/matrix interface (Lin et al., 2009). Therefore, the incorporation of $\mathrm{U}$ and $\mathrm{H}$ fibers in PVA which provide a significant improvement of all mechanical properties (strength, stiffness and ductility) is a proof of a good interfacial adhesion in our composites.

The highest improvement of tensile strength and modulus in regard to PVA (Fig. 6 and 8) was obtained for PVA/U composites, $5 \mathrm{wt} \% \mathrm{U}$ in PVA: almost 50\% and $40 \%$, respectively. The different behavior of $U$ and $H$ fibers as reinforcements in PVA could be a result of their different size (in the case of $U$ fibers, the nanosized fraction were separated from the coarse fraction) and the higher tendency to form agglomerates in the case of higher aspect ratio fibers $(\mathrm{H})$. The enhancement of mechanical properties of PVA/U and PVA/H composite films by comparison with neat PVA resulted from the good adhesion at the filler/matrix interface, favored by the small size of fibers and, accordingly, their high surface area. The hydrogen bonding between the $\mathrm{OH}$ groups of cellulose fibers and similar group of PVA matrix led to improved adhesion between phases which resulted in improved mechanical properties. Lee et al. (2009b) explained an increase of about $70 \%$ of the elastic modulus and up to $55 \%$ of the tensile strength by the intermolecular forces between cellulose fibers and PVA matrix.

b. Thermal characterization

The thermal properties of cellulose fibers reinforced PVA were determined from DSC and DTG thermograms. The main thermal transitions, glass transition temperature (Tg) and melting point (Tm), were evaluated and compared with those of the neat PVA. DSC results of PVA composites containing $5 \mathrm{wt} \%$ of cellulose fibers, $\mathrm{L}, \mathrm{H}$ and $\mathrm{U}$ types, are shown in Fig. 9.

PVA exhibits an endotherm close by $57^{\circ} \mathrm{C}\left(57.2^{\circ} \mathrm{C}\right)$ corresponding to the glass transition temperature of PVA. The appearance of one $\mathrm{Tg}$ in the nanocomposite samples highlights the good interaction of cellulose fibers and PVA in the amorphous phase. No significant changes in Tg value are observed in the case of PVA composites containing $5 \mathrm{wt} \% \mathrm{U}$ or $\mathrm{H}$ fibers as shown in Table 1, but a decrease with four degrees is detected in PVA filled with 5 $\mathrm{wt} \% \mathrm{~L}$ fibers as regard to neat PVA. This behavior is caused by the decrease of the cohesive energy density in the amorphous phase of the PVA/L composites in comparison with neat PVA and can be explained by the rupture of the hydrogen bonds in PVA because of larger 
size of L type fibers (tens of microns in diameter and hundred of microns in length). As a result, the rubbery properties and the increase of the mobility of the macromolecules will appear from lower temperatures. Nanometer sized fibers, $\mathrm{H}$ and $\mathrm{U}$, will not cause massive breaks of hydrogen bonds in PVA and, the expected interactions between these cellulose fibers and PVA will not alter the supramolecular structure of the amorphous phase. Nevertheless it seemed that these new formed interactions are not strong enough to slow the chain mobility associated with glass transition since the Tg values measured on PVA/H and PVA/U composite samples are close to that of neat PVA.

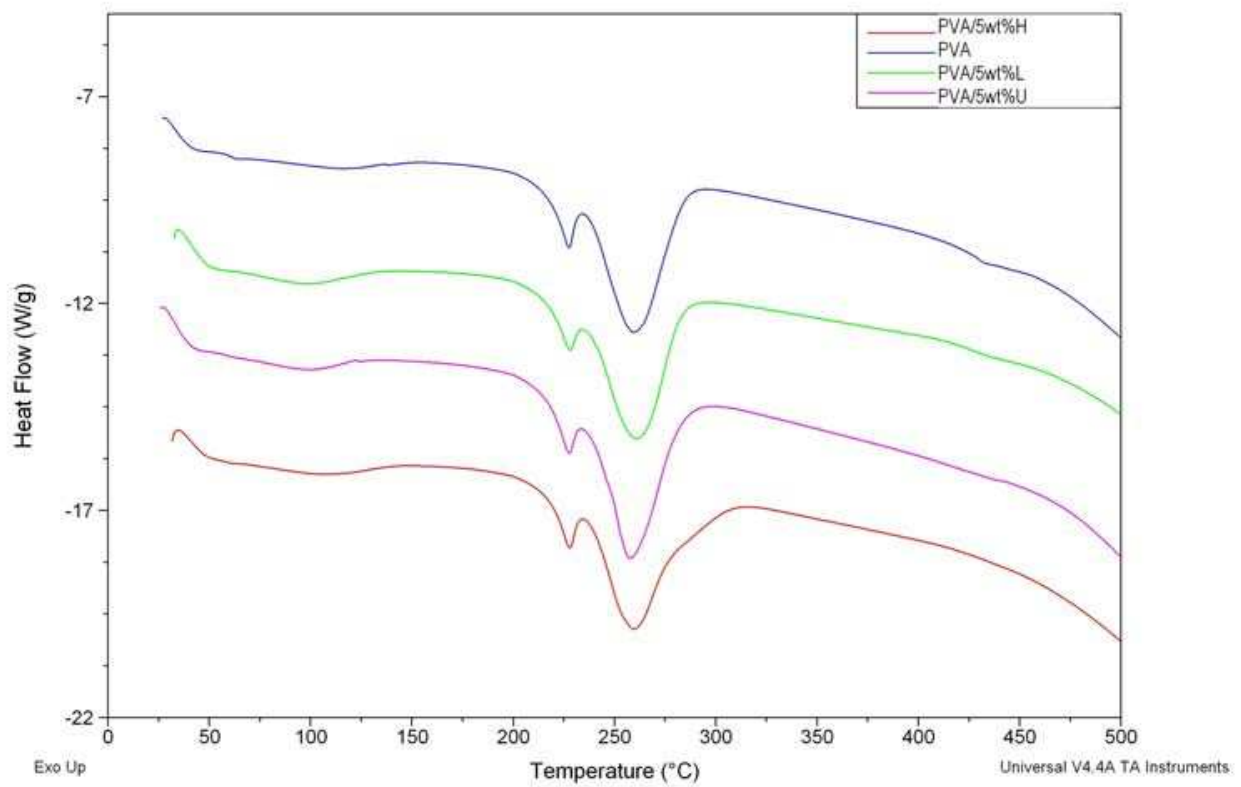

Fig. 9. DSC diagrams of neat PVA and PVA composites containing $U$, L and $H$ fibers

\begin{tabular}{|l|l|l|l|l|}
\hline Samples & $\begin{array}{l}\mathrm{Tg} \\
{ }^{\mathrm{C}}\end{array}$ & $\begin{array}{l}\mathrm{Tm} \\
{ }^{\circ} \mathrm{C}\end{array}$ & $\begin{array}{l}\Delta \mathrm{Hm} \\
\mathrm{J} / \mathrm{g}\end{array}$ & $\begin{array}{l}\mathrm{Xc}_{\mathrm{c}} \\
\%\end{array}$ \\
\hline PVA & 57.2 & 227.1 & 79.3 & 48.7 \\
\hline PVA/5\%U & 56.8 & 226.9 & 70.5 & 45.5 \\
\hline PVA/5\%L & 53.0 & 227.2 & 60.0 & 38.7 \\
\hline PVA/5\%H & 57.0 & 227.3 & 78.1 & 50.4 \\
\hline
\end{tabular}

Table 1. DSC data of neat PVA and PVA composites containing 5 wt. \% fibers 
PVA exhibits a sharp endothermic curve with a peak at $227.1^{\circ} \mathrm{C}$, as shown in Fig. 9, corresponding to the melting of the crystalline phase of PVA. Tm values remains roughly constant for all PVA composites whatever the type of fiber used but the heat of fusion is different depending on the filler characteristics. The degree of crystallinity $\left(X_{c}\right)$ of the PVA component in the composite was obtained as follows:

$$
X_{c}=\frac{\Delta H_{f}}{w * \Delta H_{0}} * 100
$$

where $\Delta H_{f}$ and $\Delta H_{o}$ are the heats of fusion for PVA and $100 \%$ crystalline PVA, respectively and $w$ is the mass fraction of PVA in the composite. $\Delta H_{o}$ was taken $163 \mathrm{~J} / \mathrm{g}$ (Ramaraj et al., 2010).

A highest degree of crystallinity is observed in PVA/H composite and the lowest in PVA/L composite. PVA filled with $\mathrm{H}$ type fibers show higher crystallinity than neat PVA. This could be ascribed to stronger interactions between cellulose fiber surface and adjacent PVA chains. The nucleating effect of cellulose fibers could also explain this increase of crystallinity. PVA/H composite shows a higher crystallinity as regard to PVA/U composite but the mechanical behavior of the latter is better. This is due to the fact that, besides the matrix crystallinity, other factors influence the tensile properties of the composite. The nanoscale dispersion of the filler and its orientation in the matrix are among these factors.

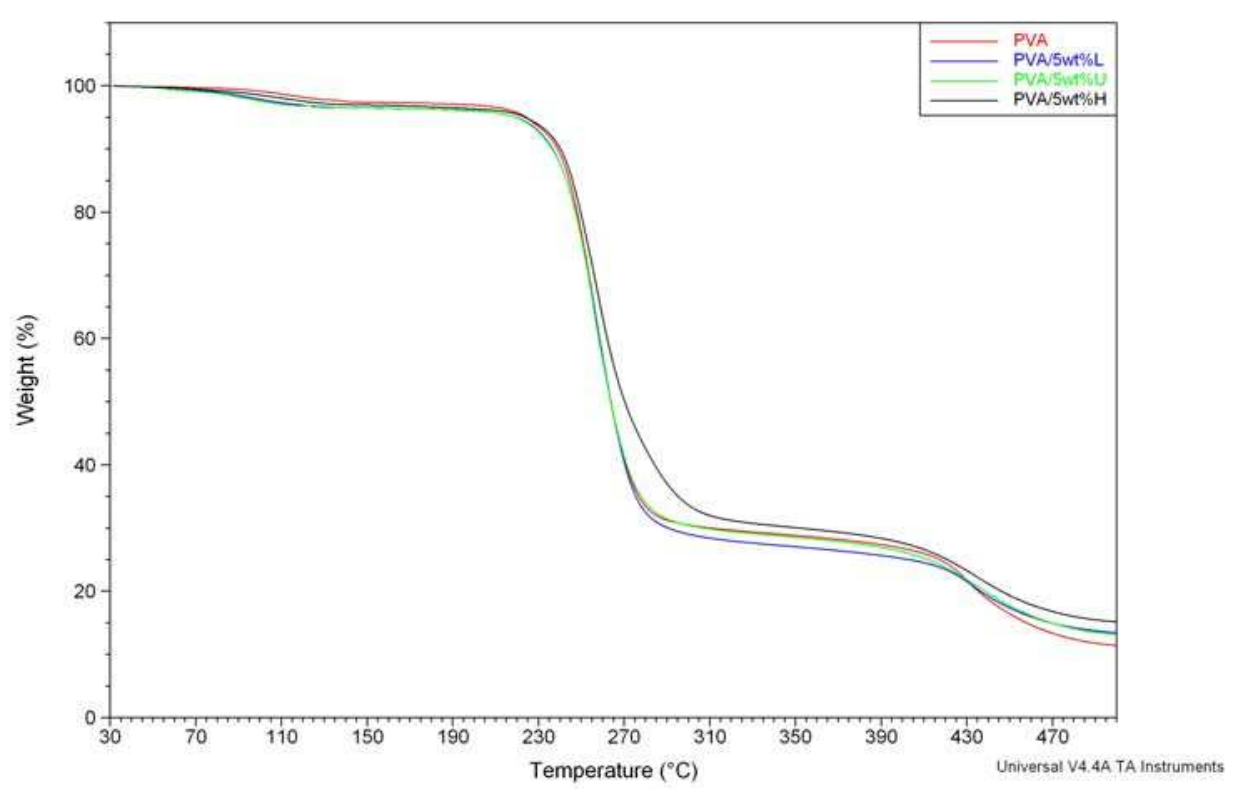

Fig. 10. TGA thermograms of neat PVA and PVA composites containing $U, L$ and $H$ fibers

Thermogravimetric analysis (TGA) was used to investigate the effect of cellulose fibers on the thermal stability of the composites. In the obtained PVA thermograms (Fig. 10) three 
main weight loss regions can be observed (Lee et al., 2009b; Qua et al., 2009). All the samples show an initial weight loss in the region $75-150{ }^{\circ} \mathrm{C}$ caused by the evaporation of water. Between 2.5 and $3.5 \mathrm{wt}$.\% physically and chemically bound water was detected in neat PVA and PVA composites thermograms. Figure shows that the second degradation region is located between 220 and $300{ }^{\circ} \mathrm{C}$ and is due to the pyrolysis of cellulose fibers and to the degradation of PVA films, the weight loss being around $70 \%$ for all the samples. As reported by Qua et al. (2009), the second stage of degradation mainly involves dehydration reactions and the formation of volatile products.

The third stage weight loss occurrs above $400{ }^{\circ} \mathrm{C}$ and consists of decomposition of carbonaceous matter (Lee et al., 2009b).

It can be observed in Fig. 10 that the differences in TGA curves are negligible for neat PVA and PVA composites. However, some differences can be detected in the case of PVA/H composite. TGA's first order derivative (Fig. 11) show a broadening of the main decomposition peak and a shift of the onset temperature for the third decomposition stage to higher temperatures. This can be due to sulfonic groups bound to the cellulose fibers by acid hydrolysis which influence the degradation process.

The onset degradation temperature $(\mathrm{Td})$ and enthalpy $(\Delta \mathrm{Hd})$ could be easily determinated from DTG curves (Table 2). Slightly higher onset degradation temperatures were obtained for PVA composites as regard to neat PVA, showing a marginal increase of the thermal stability caused by the cellulose fibers. Lee showed that the thermal stability of PVA composites was improved with the increase of the nanocellulose loading (Lee et al., 2009b).

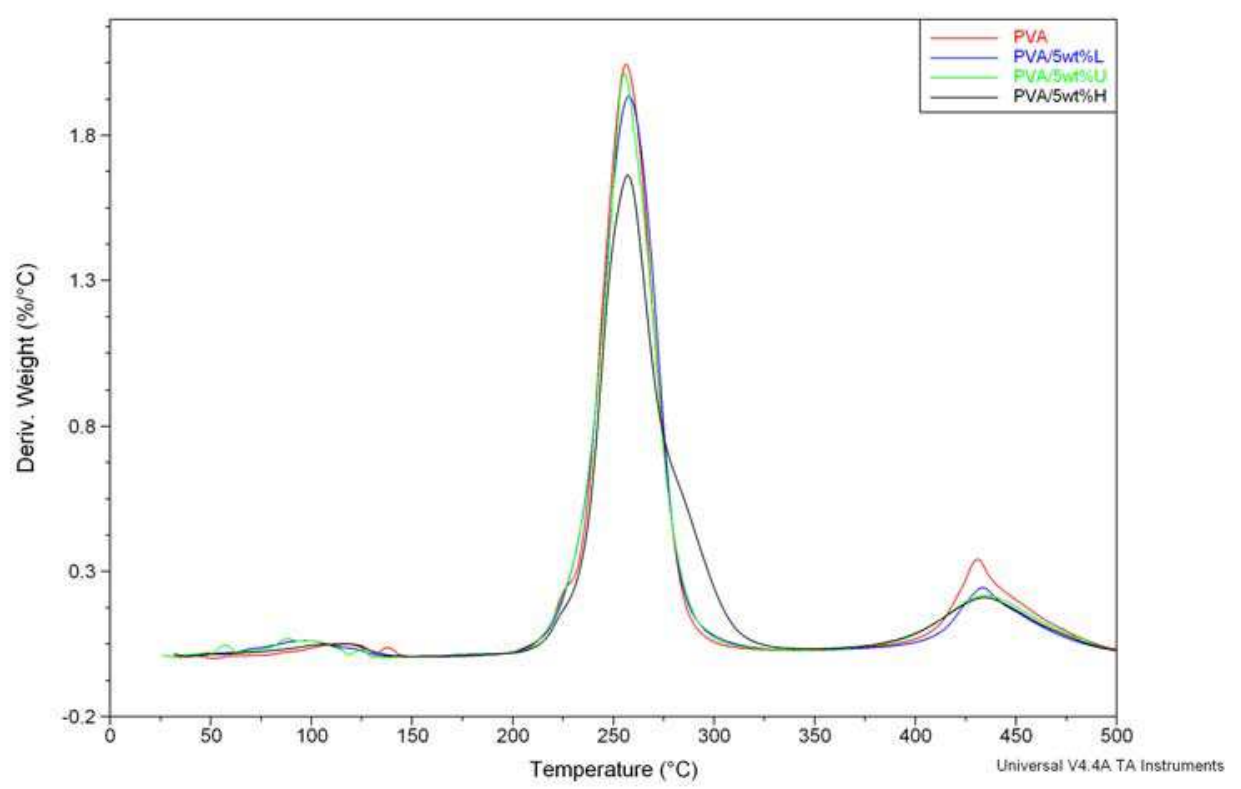

Fig. 11. DTG thermograms of neat PVA and PVA composites containing $U$, L and $H$ fibers 


\begin{tabular}{|l|l|l|}
\hline Samples & $\begin{array}{l}\mathrm{Td} \\
0 \mathrm{C}\end{array}$ & $\begin{array}{l}\Delta \mathrm{Hd} \\
\mathrm{J} / \mathrm{g}\end{array}$ \\
\hline PVA & 238.7 & 513.8 \\
\hline PVA/5\%U & 242.9 & 509.2 \\
\hline PVA/5\%L & 239.7 & 480.5 \\
\hline PVA/5\%H & 239.8 & 525.3 \\
\hline
\end{tabular}

Table 2. DSC data of neat PVA and PVA composites containing $5 \mathrm{wt} \%$ fibers

The lowered PVA/L decomposition enthalpy was thought to be related to the more complex structure of these fibers containing beside cellulose, hemicellulose and lignin and to the more porous fiber structure.

\section{Conclusion}

The application of cellulose nanofibers in polymer reinforcement is a relatively new research field. The development of fully biodegradable nanocomposites is still a challenging area.

In this chapter discussion is focused on the physical and mechanical properties of polyvinyl alcohol as a biodegradable matrix reinforced with cellulose fibers prepared by different methods. Three types of fibers with different characteristics in terms of composition, size and aspect ratio were tested as reinforcements in PVA: L fibers of micron size and high aspect ratio contain beside cellulose, hemicellulose and lignin, $\mathrm{H}$ fibers with a nanosize dimension and high aspect ratio and $U$ fibers with a nanosize dimension and low aspect ratio contain only cellulose.

These cellulose fibers were obtained by mechanical treatment, acid hydrolysis and ultrasound treatment, respectively. The isolated cellulose fibers were characterized by scanning electron microscopy (SEM) and X-ray diffraction (XRD).

Our work was focused on studying the changes induced in PVA characteristics by low concentration of these cellulose fibers. Similar conditions were applied in order to prepare PVA composite films, knowing the high influence of preparing and characterization conditions on PVA properties, in order to select the proper system PVA/cellulose fibers for a target application.

The obtained composites with low concentration of cellulose fibers (1 - 5 wt.\%) showed improved mechanical properties, preserving the transparency and flexibility of the original films. The highest improvement of the tensile strength and modulus in regard to PVA was obtained for PVA composite containing $5 \mathrm{wt} \%$ cellulose fibers prepared by ultrasound treatment: almost $50 \%$ and $40 \%$, respectively. Favorable interfacial properties and the lack of agglomerations at low fibers concentration in PVA were supposed to explain the high values of the mechanical properties.

PVA filled with acid treated cellulose fibers showed higher crystallinity than neat PVA, as resulted from DSC analysis. Stronger interactions between cellulose fiber surface and adjacent PVA chains and the nucleating effect of cellulose fibers were proposed to explain 
this increase of crystallinity. Slightly higher onset degradation temperatures were obtained for PVA composites as regard to neat PVA, showing an increase of the thermal stability caused by the addition of cellulose fibers.

The biocomposites presented in this chapter are advanced materials with improved mechanical and thermal properties, high transparency and flexibility and large possibilities of application in packaging and other fields.

Future work will be focus on the study concerning the processing behavior of these materials and on achieving new preparation methods with industrial application.

\section{References}

Alemdar, A., and Sain, M. (2008). Biocomposites from wheat straw nanofibers: Morphology, thermal and mechanical properties. Composites Sci. Technol, Vol. 68, No. 2, pp. 557-565

Andresen, M., Johansson, L. S., Tanem, B. S., and Stenius P (2006). Properties and characterization of hydrophobized microfibrillated cellulose. Cellulose, Vol. 13, pp. 665-677

Andresen, M., and Stenius, P. (2007). Water-in-oil emulsions stabilized by hydrophobized microfibrillated cellulose. J Dispers Sci Technol, Vol. 28, pp. 837-844

Belhassen, R., Mendez, J. A., Boufi, S., Lopez, J. P., Puig, J., Pelach, A., and Mutje, P. (2009). Preparation and Properties of Biocomposites Based on Jute Fibers and Blend of Plasticized Starch and Poly(b-hydroxybutyrate). Journal of Applied Polymer Science, Vol. 114, pp. 313-321

Bhatnagar, A., and Sain, M. (2005). Processing of cellulose nanofiber-reinforced composites. J Reinforced Plastics Composites, Vol. 24, No. 12, pp. 1259-1268

Bledzki, A. K., and Faruk, O. (2003). Wood Fibre Reinforced Polypropylene Composites: Effect of Fibre Geometry and Coupling Agent on Physico-Mechanical Properties. Applied Composite Materials, Vol. 10, pp. 365-379

Bledzki, A. K., Jaszkiewicz A., and Scherzer, D. (2009). Mechanical properties of PLA composites with man-made cellulose and abaca fibres. Applied Science and Manufacturing, Vol. 40, pp. 404-412

Bondeson, D., Mathew, A., and Oksman, K. (2006). Optimization of the isolation of nanocrystals from microcrystalline cellulose by acid hydrolysis. Cellulose, Vol.13, No.2, pp. 171-180

Bruce, D. M., Hobson, R. N., Farrent, J. W., Hepworth, and D. G. (2005). Highperformance composites from low-cost plant primary cell walls. Appl Sci Manufact, Vol. 36, pp. 1486-1493

Cao, X., Chen, Y., Chang, P. R., Stumborg M. and Huneault, M. A. (2008). Green Composites Reinforced with Hemp Nanocrystals in Plasticized Starch. J. of Appl. Polym. Sci., Vol. 109, No. 6, pp. 3804-3810

Chakraborty, A., Sain, M. and Kortschot, M (2005). Cellulose microfibrils: A novel method of preparation using high shear refining and cryocrushing Holzforschung, Vol. 59, pp. 102-107 
Chang, P. R., Jian, R., Zheng, P., Yu, J., and Ma, X. (2010). Preparation and properties of glycerol plasticized-starch (GPS)/cellulose nanoparticle (CN) composites. Carbohydrate Polymers, Vol. 79, pp. 301-305

Chen, Y., Liu, C., Chang, P. R., Cao, X., and Anderson, D. P. (2009). Bionanocomposites based on pea starch and cellulose nanowhiskers hydrolyzed from pea hull fiber: Effect of hydrolysis time. Carbohydrate Polymers, Vol. 76, No. 4, pp. 607-615

de Rodriguez, N. L. G., Thielemans, W., and Dufresne, A. (2006). Sisal cellulose whiskers reinforced polyvinyl acetate nanocomposites. Cellulose, Vol. 13, No. 3, pp. 261-270

Dufresne, A, and Vignon, M R (1998). Improvement of starch film performances using cellulose microfibrils. Macromolecules, Vol. 31, pp. 2693-2696

Dufresne, A., Dupeyre, D., and Vignon M. R. (2000). Cellulose microfibrils from potato tuber cells: processing and characterization of starch-cellulose microfibril composites. J Appl Polym Sci, Vol. 76, pp. 2080-2092

Dufresne, A., Dupeyre, D., and Paillet, M. (2003). Lignocellulosicflour-reinforced poly(hydroxybutyrate-co-valerate) composites. J Appl Polym Sci, vol. 87, pp. 13021315

Eichhorn, S. J., Dufresne, A., Aranguren, M., Marcovich, N. E., Capadona, J. R., Rowan, S. J., Weder, C., Thielemans, W., Roman, M., Renneckar, S., Gindl, W., Veigel, S., Keckes, J., Yano, H., Abe, K., Nogi, M., Nakagaito, A. N., Mangalam, A., Simonsen, J., Benight, A. S., Bismarck, A., Berglund L. A., and Peijs, T. (2010). Review: current international research into cellulose nanofibres and nanocomposites. Journal of Materials Science, Vol. 45, No. 1., pp. 1-33

El-Sakhawy, M., and Hassan, M. L. (2007). Physical and mechanical properties of microcrystalline cellulose prepared from agricultural residues. Carbohydrate Polymers, Vol. 67, pp. 1-10

Famá, L., Gerschenson, L., and Goyanes, S. (2009). Starch-vegetable fiber composites to protect food products. Carbohydrate Polymers, Vol. 75, No. 2, pp. 230-235

Filson, P. B., and Dawson-Andoh, B. E. (2009). Sono-chemical preparation of cellulose nanocrystals from lignocellulose derived materials. Bioresource Technology, Vol. 100, pp. 2259-2264

Ganster, J., and Fink, H. P. (2006). Novel cellulose fibre reinforced thermoplastic materials. Cellulose, Vol. 13, pp. $271-280$

Henriksson, M., Henriksson, G., Berglund, L.A., and Lindstrom, T. (2007). An environmentally friendly method for enzyme-assisted preparation of microfibrillated cellulose (MFC) nanofibers. European Polymer Journal, Vol. 43, No. 8, pp. 3434-3441

Hubbe, M. A., Rojas, O. J., Lucia, L. A. and Sain, M. (2008). Cellulosic Nanocomposites: A review. BioResources, Vol. 3, No. 3, pp. 929-980

Iwatake, A., Nogi, M., and Yano, H. (2008). Cellulose nanofiber-reinforced polylactic acid. Composites Science and Technology, Vol. 68, pp. 2103-2106

Lee, S. Y., Chun, S. J., Kang, I. A., and Park, J. Y. (2009a). Preparation of cellulose nanofibers by high-pressure homogenizer and cellulose-based composite films. Journal of Industrial and Engineering Chemistry, Vol. 15, pp. 50-55 
Lee, S. Y., Mohan, D. J., Kang, I. A., Doh, G. H., Lee, S., and Han, S. O. (2009b). Nanocellulose reinforced PVA composite films: Effects of acid treatment and filler loading. Fibers and Polymers, Vol. 10, No. 1, pp. 77-82

Leitner, J., Hinterstoisser, B., Wastyn, M., Keckes, J., and Gindl, W. (2007). Sugar beet cellulose nanofibril-reinforced composites. Cellulose, Vol. 14, pp. 419-425

Li, Y. and Pickering, K.L. (2008). Hemp fibre reinforced composites using chelator and enzyme treatments. Composites Science and Technology, Vol. 68, No. 15/16, pp. 3293-3298

Lin, N., Chen, G., Huang, J., Dufresne, A., and Chang, P. R. (2009). Effects of PolymerGrafted Natural Nanocrystals on the Structure and Mechanical Properties of Poly(lactic acid): A Case of Cellulose Whisker-graft-Polycaprolactone. J Appl Polym Sci, Vol. 113, pp. 3417-3425

Lu, J., Wang, T., and Drzal, L. T. (2008). Preparation and properties of microfibrillated cellulose polyvinyl alcohol composite materials. Appl Sci Manufact, Vol. 39, pp. 738-746

Millon, L. E., and Wan, W. K. (2006). The Polyvinyl Alcohol-Bacterial Cellulose System As A New Nanocomposite for Biomedical Applications. J Biomed Mater Res Part B: Appl Biomater, Vol. 79B, pp. 245-253

Moran, J. I., Alvarez, V. A, Cyras, V. P., and Vazquez, A. (2008). Extraction of cellulose and preparation of nanocellulose from sisal fibers. Cellulose, Vol. 15, No. 1,pp. 149-159

Nakagaito, A. N., and Yano, H. (2004). The effect of morphological chances from pulp fibers towards nano-scale fibrillated cellulose on the mechanical properties of high strength plant fiber based composites. Applied Physics A, Vol. 78, No. 4, pp. 547-552

Nakagaito, A.N., Iwamoto, S. and Yano, H. (2005). Bacterial cellulose: the ultimate nanoscalar cellulose morphology for the production of high-strength composites. Appl. Phys A, Vol. 80, No. 1, pp. 93-97

Nakagaito, A. N., and Yano, H. (2006). Novel high-strength biocomposites based on microfibrillated cellulose having nano-order-unit web-like network structure. Appl. Phys. A, Vol. 80, pp. 155-159

Panaitescu, D. M., Matasaru, I., Iovu, H., Ghiurea, M., Iorga, M. D., and Stanescu, P. (2007a). Thermoplastic Composites with Cellulose Microfibrils Obtained by Mechanical Treatments. Materiale Plastice, Vol. 44, No. 2, pp. 144-147

Panaitescu, D. M., Donescu, D., Bercu, C., Vuluga, D. M., Iorga, M. and Ghiurea, M. (2007b). Polymer Composites with Cellulose Microfibrils. Polymer Eng. Sci., Vol. 47, No. 8, pp. $1228-1234$

Pandey, J. K., Chu, W. S., Kim, C.S., Lee, C. S., and Ahn, S.H. (2009). Bio-nano reinforcement of environmentally degradable polymer matrix by cellulose whiskers from grass. Composites: Part B, Vol. 40, pp. 676-680

Petersson, L., and Oksman, K. (2006). Biopolymer based nanocomposites: Comparing layered silicates and microcrystalline cellulose as nanoreinforcement. Composites Science and Technology, Vol. 66, pp. 2187-2196 
Qua, E. H., Hornsby, P. R., Sharma, H. S., Lyons, G. and McCall, R. D. (2009). Preparation and Characterization of Poly(vinyl alcohol) Nanocomposites Made from Cellulose Nanofibers. Journal of Applied Polymer Science, Vol. 113, pp. 2238-2247

Rahman, W.A.W. A., Adenan, N., Rasit Ali, R. and Sulaiman, H. (2009). Effect of Silane Crosslinker on the Thermal Properties of Rice Straw/HDPE Biocomposite. Journal of Applied Polymer Science, Vol. 9, pp. 3041-3047

Ramaraj, B., Nayak, S. K., and Yoon, K. R. (2010). Poly(vinyl alcohol) and Layered Double Hydroxide Composites: Thermal and Mechanical Properties. J Appl Polym Sci, Vol. 116, No. 3, pp. 1671-1677

Rosa, M. F., Medeiros, E.S., Malmonge, J. A., Gregorski, K. S., Wood, D. F., Mattoso L. H. C., Glenn, G., Orts, W. J., and Imam, S. H. (2010). Cellulose nanowhiskers from coconut husk fibers: Effect of preparation conditions on their thermal and morphological behavior. Carbohydrate Polymers, Vol. 81, pp. 83-92

Sedlarık, V., Saha, N., Kuritka, I., and Saha, P. (2006). Characterization of Polymeric Biocomposite Based on Poly(vinyl alcohol) and Poly(vinyl pyrrolidone). Polym Compos, Vol. 27, pp. 147-152

Shaikh, H., Pandare, M. K. V., Nair, G., and Varma, A. J. (2009). Utilization of sugarcane bagasse cellulose for producing cellulose acetates: Novel use of residual hemicellulose as plasticizer. Carbohydrate Polymers, Vol. 76, No. 1, pp. 23-29

Siro, I., and Plackett, D. (2010). Microfibrillated cellulose and new nanocomposite materials: a review. Cellulose, Vol. 17, pp. 459-494

Stenstad P, Andresen M, Tanem BS, Stenius P (2008) Chemical surface modifications of microfibrillated cellulose. Cellulose, Vol. 15, pp. 35-45

Suryanegara, L., Nakagaito, A. N., and Yano, H. (2009). The effect of crysatllization of PLA on the thermal and mechanical properties of microfibrillated cellulosereinforced PLA composites. Composites Science and Technology, Vol. 69, pp. 11871192

Tang, Y., Du, Y., Li, Y., Wang, X., and Hu, X. (2009). A thermosensitive chitosan/poly(vinyl alcohol) hydrogel containing hydroxyapatite for protein delivery. J Biomed Mater Res, Vol. 91A, pp. 953-963

Taniguchi, T. and Okamura, K. (1998). New films produced from microfibrillated natural fibres. Polym Int, Vol. 47, pp. 291-294

Yanjun, X., Hill, C. A. S., Xiao, Z., Militz, H., and Mai, C. (2010). Silane coupling agents used for natural fiber/polymer composites: A review. Applied Science and Manufacturing, Vol. 41, pp. 806-819

Yano, S., Maeda, H., Nakajima, M., Hagiwara, T., and Sawaguchi, T. (2008). Preparation and mechanical properties of bacterial cellulose nanocomposites loaded with silica nanoparticles. Cellulose, Vol. 15, No. 1, pp. 111-120

Zhang, J., Elder, T. J., Pu, Y., and Ragauskas, A. J. (2007). Facile synthesis of spherical cellulose nanoparticles. Carbohydrate Polymers, Vol. 69, pp. 607-611

Zhou, W. Y., Guo, B., Liu, M., Liao, R., Rabie, B. A. M., and Jia, D. (2010). Poly(vinyl alcohol)/Halloysite nanotubes bionanocomposite films: Properties and in vitro osteoblasts and fibroblasts response. J Biomed Mater Res , Poly(vinyl 
alcohol)/Halloysite nanotubes bionanocomposite films: Properties and in vitro osteoblasts and fibroblasts response, Vol. 93A, pp. 1574-1587

Zimmermann, T., Pöhler, E. and Geiger, T. (2004). Cellulose Fibrils for Polymer Reinforcement. Advanced Engineering materials, Vol. 6, no. 9, pp. 754-761

Zuluaga, R., Putaux, J. L., Cruz, J., Vélez, J., Mondragon, I., and Gañán, P. (2009). Cellulose microfibrils from banana rachis: Effect of alkaline treatments on structural and morphological features. Carbohydrate Polymers, Vol. 76, pp. 51-59 


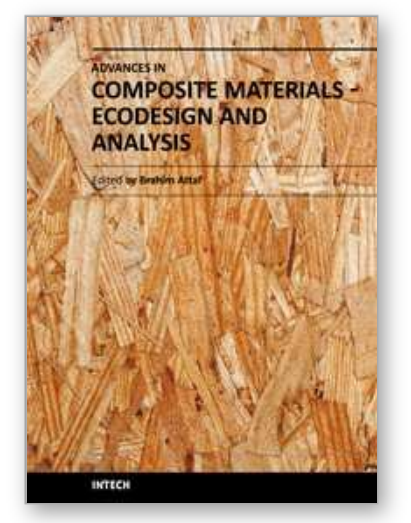

\author{
Advances in Composite Materials - Ecodesign and Analysis \\ Edited by Dr. Brahim Attaf
}

ISBN 978-953-307-150-3

Hard cover, 642 pages

Publisher InTech

Published online 16, March, 2011

Published in print edition March, 2011

By adopting the principles of sustainable design and cleaner production, this important book opens a new challenge in the world of composite materials and explores the achieved advancements of specialists in their respective areas of research and innovation. Contributions coming from both spaces of academia and industry were so diversified that the 28 chapters composing the book have been grouped into the following main parts: sustainable materials and ecodesign aspects, composite materials and curing processes, modelling and testing, strength of adhesive joints, characterization and thermal behaviour, all of which provides an invaluable overview of this fascinating subject area. Results achieved from theoretical, numerical and experimental investigations can help designers, manufacturers and suppliers involved with high-tech composite materials to boost competitiveness and innovation productivity.

\title{
How to reference
}

In order to correctly reference this scholarly work, feel free to copy and paste the following:

Denis Mihaela Panaitescu, Adriana Nicoleta Frone, Marius Ghiurea, Catalin llie Spataru, Constantin Radovici and Michaela Doina lorga (2011). Properties of Polymer Composites with Cellulose Microfibrils, Advances in Composite Materials - Ecodesign and Analysis, Dr. Brahim Attaf (Ed.), ISBN: 978-953-307-150-3, InTech, Available from: http://www.intechopen.com/books/advances-in-composite-materials-ecodesign-andanalysis/properties-of-polymer-composites-with-cellulose-microfibrils

\section{INTECH}

open science | open minds

\section{InTech Europe}

University Campus STeP Ri

Slavka Krautzeka 83/A

51000 Rijeka, Croatia

Phone: +385 (51) 770447

Fax: +385 (51) 686166

www.intechopen.com

\section{InTech China}

Unit 405, Office Block, Hotel Equatorial Shanghai

No.65, Yan An Road (West), Shanghai, 200040, China

中国上海市延安西路65号上海国际贵都大饭店办公楼 405 单元

Phone: +86-21-62489820

Fax: $+86-21-62489821$ 
(C) 2011 The Author(s). Licensee IntechOpen. This chapter is distributed under the terms of the Creative Commons Attribution-NonCommercialShareAlike-3.0 License, which permits use, distribution and reproduction for non-commercial purposes, provided the original is properly cited and derivative works building on this content are distributed under the same license. 